\title{
Children's Right to Health: Theory versus Practice
}

\author{
Ilaria Simonelli
}

\begin{abstract}
Introduction A research was conducted from 2014 to 2018 to understand the reasons behind the gap between the theoretical affirmation of children's right to health and its practical realization. Hospitals and healthcare services were chosen as possible settings to understand these reasons and identify the gap.

Method Questionnaires (open-ended questions) were completed throughout the year 2017 with experts working at International level in the field of children's rights. A survey was set up using a structured multiple-choice questionnaire in Italian, English, and French. The survey was addressed to hospital staff (professionals; managers and administrative staff). All the results from the experts' questionnaires and from the survey were elaborated using Excel.

Results Experts concluded that professionals still have to understand the full value of implementing children's rights in hospitals and that the United Nations should empower their own action in order to push states towards the respect and full realization of the Convention on the Rights of the Child. The survey results seem to confirm that in healthcare settings professionals' have difficulties in understanding how to relate to children in order to facilitate the full realization of their right to health.

Conclusion The investigation confirmed the existence of a 'perceptive astigmatism' as guiding factor for professionals' behaviour towards children.

Submitted:

Accepted:

Published online:

2 September 2020

18 June 2021

24 August 2021
\end{abstract}

\section{About the AUTHOR}

Coordinator of the Task Force HPH-CA for Health promotion of children and adolescents, HPH Network, Trento, Italy.

Contact: Ilaria Simonelli ilariasimonelli79@gmail.com

\section{Introduction}

The UN Convention on the Rights of the Child (CRC) (1) is one of the most recognized Conventions worldwide with more than 190 Countries having agreed upon its contents. Nevertheless, it is possibly also one of the most violated. If we start by looking at the broad framework of human rights in general, we can see that many violations have been registered. Amnesty International (2) recorded violations of human rights in 160 countries in 2014; war crimes had been committed in at least 18 countries; armed groups had committed abuses in at least 35 countries; 62 countries had imprisoned people who exercised their rights and freedoms; 3 governments out of 4 had arbitrarily restricted freedom of expression, with particular reference to freedom of the press; $82 \%$ of countries had tortured or abused people; 93 countries out of 160 had conducted unfair trials. With regard to the right to health in particular, a comparative analysis (3) conducted in 194 health systems worldwide has shown that 121 countries do not recognize it within their own constitutions, even if they have signed at least an international treaty confirming the country's intention to protect it and promote it, while a survey conducted in the UK has instead confirmed how the application and implementation of a human rights based approach has positive effects on the treatment and care of patients within health systems in terms of policies, practices and services rendered to the population (4). With particular reference to children, the Convention on the Rights of the Child encountered numerous and serious violations and a concrete testimony of this affirmation is given by the discre- 


\section{Research and Best Practice}

pancy Article 19 of the convention on protection from violence and the spread of female genital mutilations in several countries of the world (5). All these data, and possibly their update during the years, suggest that, in spite of formal and political declarations of commitment, there are still huge difficulties in making human rights and children's rights a solid reality worldwide. In this paper we aimed to understand the reasons of the gap between the international affirmation of the importance of children's rights and their practical realization in a defined setting (healthcare services) and for a defined right (right to health).

This particular research question is important in order to understand healthcare professionals' attitudes towards children.

\section{Methodology}

The methodology consisted of a mixed qualitative and quantitative approach.

\section{Questionnaires}

Questionnaires with open-ended questions (qualitative) were completed throughout the year 2017 with experts working in the field of children's rights at International level (United Nations Consultants; Healthcare managers; NGOs representatives). A grid of open-ended questions was prepared in Italian and in English. The researcher asked experts to respond directly via Skype but time and constraints in their schedules did not allow it. For this reason, the questionnaires were sent via e-mail by the researcher to the experts, a deadline was fixed with the experts who filled in the word sheet independently and sent it back to the researcher for format adjustments and for elaboration of the information. One expert found the time to respond to the questionnaire in person via Skype. All questionnaires were checked by the researcher, approved by the experts, transcribed in Excel and analysed by the researcher using a gridline of content analysis (6) in order to individuate common pathways among experts. The goal of the researcher was to check if common opinions/evaluations existed among the experts in terms of critical issues determining the gap between declared principles and reality (e.g. all the experts agreed on the fact that the UN system needs to be more efficient in making countries respect children's rights). Experts approved the final version of their questionnaire answers (after format revision, language corrections, request for unclear terms or concepts) and checked the systematization made by the researcher on all questionnaires. The

1 For example: Children have the right to access health services without ethnic racial, class, religious, gender, age, sexual orientation, disability, language, cultural and social discrimination; Children shall be admitted to the hospital only if the care they require cannot be equally well provided and effective at home or on a expert who answered directly to the questionnaire via Skype confirmed the transcription made by the researcher as well. The questions for the experts referred to: the gap between principles and actions in terms of respect of children's right to health; the critical aspects of national policies in terms of implementation; the main factors playing a role in reducing the gap; the main obstacles to the convention principles (development and survival, non-discrimination, right to be heard, and best interest of the child); main obstacles to children's active participation in healthcare systems (see appendix).

\section{Survey}

A survey (quantitative) with a structured multiple-choice questionnaire was distributed in Italian, English and French, addressed to hospital staff (professionals; managers and administrative staff). These three languages were chosen in order to allow the researcher to translate directly the tools without any additional costs applied to the research for translation purposes. The questionnaire was self-administered and was prepared on the track of an already tested and validated tool - the Self Evaluation Model and Tool (SEMT) developed by the International Task Force Health Promotion for and with Children and Adolescents (HPH-CA) of the International Network Health Promoting Hospitals (HPH). The questionnaire was composed by 13 questions; each one was referred to a specific right mentioned in the Convention on the Rights of the Child in order to understand the level of achievement in a specific hospital or healthcare setting ${ }^{1}$ (significantly achieved; slightly considered; meaningful progress; completely unconsidered). The tool also contained one multiple-choice question to understand the main obstacles to the realization of the child's right to health and six Likert scales (1 to 10) in order to understand the level of priority of the strategies addressed to promoting child's right to health compared to other hospital strategies (quality improvement; research; ICTs development; Budget policies; etc.).

For the recruitment of professionals from European hospitals and paediatric departments, the researcher was supported by the HPH (Health Promoting Hospitals) Network - in particular the members of the HPH-CA Task Force, and by representatives of the European Association for Children in Hospital (EACH). A total of eighty general management offices of EU hospitals were contacted directly by the researcher and a total of 19 responded positively and participated in the survey. The professionals were chosen with cluster sampling: the management

day basis; Children have the right to have full opportunity for play, rest, leisure recreation and education suited to their age and condition and to be in an environment designed, furnished, staffed and equipped to meet their needs; etc. 


\section{Research and Best Practice}

level; the clinical level; the administration level. A total of 115 professionals responded. Data were elaborated with Excel for a statistical descriptive analysis of the provided answers. The university checked and approved the data collection and elaboration, according to the Bologna University Ethical Code of Behaviour. All data were handled in anonymity. The names of the respondents were protected by privacy and a number was assigned to each answer. Anonymity was guaranteed to respondents before collecting the information.

\section{Results}

Results are twofold:

\section{Questionnaires to experts}

The content analysis carried out by the researcher highlighted common key concepts/themes among the respondents (conceptual analysis on themes). If the concept/theme appeared at least twice throughout all the questionnaires, it was considered as an agreed area between the experts. In particular, four common pathways were found (areas of agreement between professionals).

1) Targeted professional training is necessary to make health professionals understand the importance of ensuring the right to health of the child in the hospital context. To reach this goal it is necessary to produce evidence on violations to the respect of the child's right to health through appropriate monitoring and evaluation tools.

2) The evaluation of the quality of healthcare services must include the aspects connected to the right to health, such as interpersonal relationships, information and listening to the child, with particular regard to her/his health status (for example through informed consent).

3) It is necessary to develop a vision and an inter-sectoral action that involves all the policies having an impact on the health of the child (not only those in the healthcare area).

4) The United Nations Agencies must become more effective in technical support to countries by overcoming their internal operational fragmentation. They also should have more coercive powers with noncompliant states. In particular, the United Nations and also states should prevent and combat the conditions of poverty in which children live, which are a threat to the enforceability and exercise of their rights. Sometimes, in fact, social inequalities cause direct effects on the health and well-being of children $(7 ; 8)$.

\section{Survey results}

A total of 115 questionnaires were collected among 19 participating hospitals and healthcare services from 10 countries: Vatican City (30\%), Italy (28\%), Portugal $(10 \%)$, Spain (10\%), Finland (1\%) Estonia (7\%), Holland (7\%), Austria (3\%), France (3\%), Germany (1\%). The participation varied among countries - as indicated by the $\%$ of filled in questionnaires - and this aspect should be considered in the interpretation of the results. The professional profile of the respondents appears to be quite varied: nurses (43\%), doctors (25\%), managers (general managers, department managers, hospitals inside clinics, and management profiles in general) (10\%), nursing coordinators (4\%), administrative staff (4\%), educators (3\%), consultants (3\%), social assistants (2\%), physiotherapists (1\%). The average value (on a scale from 1 to 10 ) of the evaluation on all profiles made in terms of importance for the hospital policies of the children's rights agenda was positive (table 1):

Table 1. Self-evaluation on the level of importance of hospital policies on children's rights (on a scale from 1 to 10 )

\begin{tabular}{lc} 
Professional role & $\begin{array}{c}\text { Policy on children's rights } \\
\text { (average) }\end{array}$ \\
\hline Administrative staff & 9,0 \\
Social assistant & 9,0 \\
Consultant & 9,3 \\
Coordinating nurse & 9,2 \\
Educator & 9,7 \\
Physiotherapists & 8,0 \\
Nurse & 8,8 \\
Manager & 8,5 \\
Physician & 8,3 \\
Not specified & 8,0 \\
\hline Total & 8,6 \\
\hline
\end{tabular}

Similarly, the large majority of the hospitals had a Charter on the rights of the children, but a child friendly version of the Charter was lacking in about half of the hospitals (see table 2).

Table 2. Self-evaluation on the policy for children's rights (total of respondents per chosen value) SCALE (1 TO 10)

$$
\begin{array}{lllllllllll}
1 & 3 & 4 & 5 & 6 & 7 & 8 & 9 & 10 & \text { Missing } & \text { Total }
\end{array}
$$

Is there a child friendly version of the Charter on children's rights in hospitals?

\begin{tabular}{lccccccccccc} 
No & & & 1 & 4 & 2 & 6 & 12 & 15 & 26 & & 66 \\
Yes & 1 & & & 1 & & 4 & 10 & 6 & 16 & 2 & 40 \\
Missing & & 1 & & & & 1 & & 2 & 5 & & 9 \\
\hline Total & 1 & 1 & 1 & 5 & 2 & 11 & 22 & 23 & 47 & 2 & 115
\end{tabular}

Is there a Charter on the rights of the child in hospitals?

$\begin{array}{llllllll}\text { No } & 3 & 1 & 1 & 2 & 1 & 2 & 10\end{array}$

$\begin{array}{llllllllllll}\text { Yes } & 1 & 1 & 1 & 2 & 1 & 10 & 20 & 22 & 45 & 2 & 105\end{array}$

\begin{tabular}{llllllllllll} 
Missing & & & & & & & & & & & \\
Total & 1 & 1 & 1 & 5 & 2 & 11 & 22 & 23 & 47 & 2 & 115 \\
\hline
\end{tabular}




\section{Research and Best Practice}

Interestingly, the achievement of children's rights in hospitals were significantly achieved for the vast majority (see table 3).

Table 3. Level of achievement of children's rights in hospitals

\begin{tabular}{lc}
\hline Options & $\%$ \\
\hline Significantly achieved & 71 \\
Meaningful progress & 22 \\
Slightly considered & 5 \\
Completely unconsidered & 1 \\
No answer & 1 \\
\hline Total & 100 \\
\hline
\end{tabular}

The detailed self-evaluation prospect for all the children's rights showed positive results (see table 4).

\section{Discussion}

Of the 105 professionals who provided a positive judgment about hospital policies on children's rights, 61 responded 'no' to the question concerning the presence of a Charter that could be consulted by children themselves.

Crossing the frequency of the responses registered on the self-evaluation of the hospital policy on the rights of the child (on a scale from 1 to 10 ) with those relating to the presence of the child friendly version of the Hospital Charter of rights (yes/no answer), the majority of respondents confirmed the absence of the child friendly version of the Charter (table 2).

This means that even if, for example, 26 professionals answered with a 10 on the scale stating the importance for the hospital of a policy on the rights of the child, they also answered 'no' to the presence of the friendly version of the Charter. So, how can such a high evaluation on hospital policies (10) be consistent with the absence of an important tool (the Charter) useful for its realization?

This means that even if, for example, 26 professionals answered with a 10 on the scale stating the importance

Table 4. Summary of all the rights achievement level (\%). Light blue indicates critical aspects.

\begin{tabular}{|c|c|c|c|c|c|c|c|c|c|c|c|c|}
\hline & \multicolumn{2}{|c|}{$\begin{array}{l}\text { Significantly } \\
\text { achieved }\end{array}$} & \multicolumn{2}{|c|}{$\begin{array}{l}\text { Meaningful } \\
\text { progress }\end{array}$} & \multicolumn{2}{|c|}{$\begin{array}{c}\text { Slightly } \\
\text { considered }\end{array}$} & \multicolumn{2}{|c|}{$\begin{array}{c}\text { Completely } \\
\text { unconsidered }\end{array}$} & \multicolumn{2}{|c|}{ Missing } & \multicolumn{2}{|c|}{ Total } \\
\hline & $\mathrm{N}$ & $\%$ & $\mathrm{~N}$ & $\%$ & $\mathrm{~N}$ & $\%$ & $\mathrm{~N}$ & $\%$ & $\mathrm{~N}$ & $\%$ & $\mathrm{~N}$ & $\%$ \\
\hline $\begin{array}{l}\text { Children's health care provision should take into considera- } \\
\text { tion all dimensions of health, including physical, mental, } \\
\text { social, cultural and spiritual }\end{array}$ & 83 & 72.2 & 25 & 21.7 & 6 & 5.2 & 0 & 0.0 & 1 & 0.9 & 115 & 100 \\
\hline $\begin{array}{l}\text { Children have the right to access health services without } \\
\text { ethnic, racial, class, religious, gender, age, sexual orienta- } \\
\text { tion, disability, language, cultural and social discrimination }\end{array}$ & 100 & 87.0 & 13 & 11.3 & 2 & 1.7 & 0 & 0.0 & 0 & 0.0 & 115 & 100 \\
\hline $\begin{array}{l}\text { Children shall be admitted to the hospital only if the care } \\
\text { they require cannot be equally well provided and effective } \\
\text { at home or on a day basis }\end{array}$ & 68 & 59.1 & 37 & 32.2 & 8 & 7.0 & 0 & 0.0 & 2 & 1.7 & 115 & 100 \\
\hline $\begin{array}{l}\text { Children have the right to have full opportunity for play, } \\
\text { rest, leisure, recreation and education suited to their age } \\
\text { and condition and to be in an environment designed, fur- } \\
\text { nished, staffed and equipped to meet their needs }\end{array}$ & 69 & 60.0 & 34 & 29.6 & 10 & 8.7 & 0 & 0.0 & 2 & 1.7 & 115 & 100 \\
\hline $\begin{array}{l}\text { Children have the right to be informed in a manner appro- } \\
\text { priate to their age, developmental level and understanding }\end{array}$ & 81 & 70.4 & 26 & 22.6 & 7 & 6.1 & 1 & 0.9 & 0 & 0.0 & 115 & 100 \\
\hline $\begin{array}{l}\text { Children have the right to express freely their opinions on } \\
\text { any issue that involves them and the right to be heard and } \\
\text { to be taken into consideration in a way consistent with } \\
\text { their age and maturity }\end{array}$ & 74 & 64.3 & 30 & 26.1 & 9 & 7.8 & 1 & 0.9 & 1 & 0.9 & 115 & 100 \\
\hline $\begin{array}{l}\text { Children have the right to be protected from all forms of } \\
\text { physical or mental violence, injury or abuse, neglect or } \\
\text { negligent treatment, maltreatment or exploitation, includ- } \\
\text { ing sexual abuse }\end{array}$ & 96 & 83.5 & 17 & 14.8 & 2 & 1.7 & 0 & 0.0 & 0 & 0.0 & 115 & 100 \\
\hline $\begin{array}{l}\text { Children have the right not to be separated from their par- } \\
\text { ents/guardians/caregivers against their will during their } \\
\text { stay in hospital }\end{array}$ & 100 & 87.0 & 13 & 11.3 & 2 & 1.7 & 0 & 0.0 & 0 & 0.0 & 115 & 100 \\
\hline Children have the right to privacy & 72 & 62.6 & 31 & 27.0 & 12 & 10.4 & 0 & 0.0 & 0 & 0.0 & 115 & 100 \\
\hline Children have the right to a dignified death & 79 & 68.7 & 25 & 21.7 & 6 & 5.2 & 4 & 3.5 & 1 & 0.9 & 115 & 100 \\
\hline Children have the right not to feel pain & 73 & 63.5 & 37 & 32.2 & 4 & 3.5 & 0 & 0.0 & 1 & 0.9 & 115 & 100 \\
\hline $\begin{array}{l}\text { Children have the right not to be submitted to clinical re- } \\
\text { search or experimentation projects and to have the possi- } \\
\text { bility to withdraw during the process of research }\end{array}$ & 84 & 73.0 & 20 & 17.4 & 7 & 6.1 & 2 & 1.7 & 2 & 1.7 & 115 & 100 \\
\hline
\end{tabular}




\section{Research and Best Practice}

for the hospital of a policy on the rights of the child, they also answered 'no' to the presence of the friendly version of the Charter. So, how can such a high evaluation on hospital policies (10) be consistent with the absence of an important tool (the Charter) useful for its realization?

Still, the $71 \%$ of respondents declares that the rights of the child proposed in the questionnaire were accomplished in a meaningful way (see table 3 ). This result shows that perhaps there is not enough clarity on how to achieve the full realization of the rights of the child.

If we look at the whole self-evaluation prospect for all the children's rights, we can see it shows positive results, even if some aspects are still considered critical by respondents (see results in table 4, marked in light blue).

Of course, this being a self-evaluation, results are not objective and, as we saw from the example of Table 2 , it is possible that professionals still don't have a clear idea of children's rights or hospital policies on children's rights.

Many contradictions seem to be present in the results. First of all, the high importance (average value) given to hospital policies on children's rights seem to be incoherent with the fact that a Charter is often not available in a child friendly version. How is it possible to achieve a high attention of hospitals settings to children's rights when not even a child friendly version of the charter is provided?

Maybe this can be explained by the fact that this aspect is not considered as a good indicator of implementation of children's rights. Perhaps the child is perceived by professionals as a passive actor in a therapeutic relationship, completely represented by parents.

Hughes (9) reports an interesting distinction between the concept of profession and that of science, defining the latter as the context within which the scholar deals with colleagues who share his own knowledge and with whom he can have a balanced and equal dialogue. Conversely, the concept of profession relates more to sharing knowledge with patients (not colleagues), with a different kind of authority. The profession does not confess its limits to the patient, this happens only in a scientific environment among colleagues. This attitude helps avoiding criticism or possible accusations of low competence by patients. Providing little information to the patient, for example, can help professions to avoid being criticized and, as Freidson (10) would say, it avoids a clash of perspectives between mismatched points of view.

Together with the results, there is also a body of evidence confirming the systematic exclusion of children and adolescents from decision-making processes in health settings (11-13) as well as from information processes related to their own health (14-17). Observational studies have also shown how professionals prefer to provide information to parents, rather than to children themselves, relegating them to an exclusion status (18-20). Finally, it is necessary to underline the need to restore an empathic relationship with patients, meaning empathy "to guide the relationship towards warmth, intelligibility and adherence to care where a cold and impersonal, even if professional, relationship would be experienced (...) as detached and alienating" (21).

\section{Limitations of the Study}

The research presents several limitations:

1) The questionnaire with experts had to be sent via email as professionals were just too busy to program Skype calls so they preferred to arrange their schedule freely to fill in the questionnaire independently. This aspect made it impossible to have a direct dialogue with experts and to record answers for a following more precise transcription. It also made impossible for the researcher to deepen key issues or critical aspects.

2) Quantitative analysis is based on a self-evaluation and the researcher did not have the possibility to evaluate directly the situation described by respondents.

3) Children's participation and point of view was not registered as protection principles are still stronger that participation.

\section{Perspectives}

The lack of a common vision aimed at the implementation of rights, including those of minors, seems to be due to the absence of a central social actor capable of leading this process. This gap could perhaps be filled also thanks to a unified approach of the different scientific disciplines able to direct the public attention towards the application of human rights. In this sense, it must be added that even sociology is not exempt from responsibility: as Blumer states (22) 'in identifying social problems sociologists tend to focus attention on phenomena only when they become the center of public concern', and much less - it can be added - to bring out the central issues for society when they are not yet obvious, perhaps expressing in this case the need for a concrete sociology of human rights'.

\section{Conclusions}

To summarize, we can notice the following aspects, especially from the survey: 


\section{Research and Best Practice}

1) Policies for the respect of the rights of the child are generally evaluated as very important and meaningfully achieved in hospital settings.

2) The right of children to health in the hospital is, in many cases, considered as achieved in a significant way, even if a Charter of children's rights is not available and cannot be consulted by the minors themselves. This phenomenon, that we could define as 'perceptive astigmatism', has been confirmed by research data and appears to be common in countries involved in the research.

3) The aforementioned professional 'perceptive astigmatism' could be explained by a 'corporate resistance' of the health professions in recognizing their own limits in listening to the child's views and in verifying the level of understanding of information provided by professionals to the child.

4) Professionals' training on children's rights is still considered insufficient, as well as the professionals' attitude in promoting the full participation of hospitalized children to their own care.

The research results (qualitative and quantitative) represent a small contribution to prove how much the issue of children's rights still fails to be framed as a relevant and pivotal issue for society, despite the existing ethical, social and cultural reasons. States and international organizations are still not able to fully implement respect for human rights; adult society is not able to correctly perceive the importance of children's rights; health and social care professionals sometimes fail to fully translate children's right to health in hospital settings. The growing but fragmented sensitivity expressed by some associations, institutional bodies and social groups for this issue is not yet sufficient to make it a central social issue, and for this reason it can be said that we are facing a challenge that has not yet been won.

Competing interests: None declared.

Funding: None declared.

Patient content: Not applicable.

Ethics approval: Not applicable.

Availability of data and materials: Data can be consulted after contacting the author.

\section{References}

(1) UN General Assembly (1989), Convention on the Rights of the Child, New York. Available at: https://www.ohchr.org/en/ professionalinterest/pages/crc.aspx.

(2) Amnesty International Report 2014/15, The State Of The World's Human Rights. Available at: https://www.amnesty.org/en/ documents/pol10/0001/2015/en/.

(3) Backman G, et al. Health Systems and the Right to Health: An Assessment of 194 Countries. Lancet. 2008; 372:2047-85. doi:10.1016/ S0140-6736(08)61781-X.

(4) Dyer L. A Review of the Impact of the Human Rights in Healthcare Programme in England and Wales. Health and Human Rights 2015: 17/2. https://www.hhrjournal.org/2015/12/a-review-of-the-impactof-the-human-rights-in-healthcare-programme-in-england-andwales/.

(5) UNICEF (2013) Female Genital Mutilation/Cutting: a statistical overview and exploration of the dynamics of change, Geneva. Available at: https://data.unicef.org/resources/fgm-statisticaloverview-and-dynamics-of-change/.

(6) Krippendorff K. Content Analysis: An Introduction to its Methodology. Beverly Hills, Sage Publications, 1980.

(7) Cersosimo G. Salute e disuguaglianze: percorsi analitici [Health and inequalities: analytical pathways]. Milano, Franco Angeli, 2012.

(8) Bergamaschi M. Ritorno dell'incertezza e nuovi rischi di impoverimento, in Sociologia urbana e rurale, Fascicolo 5, [Return of uncertainty and new risks of impoverishment, in Urban and Rural Sociology]. Minano, Franco Angeli, 2001.

(9) Hughes EC. The Sociological Point of View in The Sociological Eye. Chicago, Aldine Atherton, 1964.

(10) Freidson E. Profession of Medicine: A Study of the Sociology of Applied Knowledge, University of Chicago, Chicago Press, 1970.

(11) Carter B. Chronic Pain in Childhood and the Medical Encounter: Professional Ventriloquism and Hidden Voices. Qual Health Res. 2002; 12:28-41. doi:10.1177/104973230201200103.

(12) Shiminski-Maher T. (1993), Physician-Patient-Parent Communication Problems. Pediatr Neurosurg. 1993; 19:104-8. doi:10.1159/ 000120710.

(13) van Dulmen AM. Children's Contributions to Pediatric Outpatient Encounters. Pediatrics. 1998; 102:563-8. doi:10.1542/ peds.102.3.563.

(14) Alderson P. Children's Consent to Surgery. Oxford, Oxford University Press, 1993.

(15) Alderson P. Choosing for Children: Parents' Consent to Surgery. Oxford, Oxford University Press, 1990.

(16) Beresford BA, Sloper P. Chronically III Adolescents' Experiences of Communicating with Doctors: A Qualitative Study. J Adolesc Health. 2003; 33:172-9. doi:10.1016/s1054-139x(03)00047-8.

(17) Epstein LT, Wayman KI. Interruptions in Development: The Communicative Context of the Young Hospitalized Child. Inf Young Children 1998: 10;32-43. doi:10.1097/00001163-199810030-00007.

(18) Savage E, Callery P. Clinic Consultations with Children and Parents on the Dietary Management of Cystic Fibrosis. Soc Sci Med. 2007; 64:363-74. doi:10.1016/j.socscimed.2006.09.003.

(19) Tates K, Meeuwesen L. Doctor-Parent-Child Communication: A (Re)view of the Literature. Soc Sci Med. 2001; 52:839-51. doi:10.1016 /s0277-9536(00)00193-3.

(20) Wassmer E, Minnaar G, Atkinson M, Gupta E, Yuen S, Rylance G. How Do Paediatricians Communicate with Children and Parents? Acta Paediatr. 2004; 93:1501-6. doi:10.1080/08035250410015079.

(21) Maturo A. La sociologia della malattia in Achille Ardigò e nei classici della sociologia della salute [The sociology of disease in Achille Ardigò and in the classics of the sociology of health]. Milano, Franco Angeli, 2009.

(22) Blumer H. Social Problems as Collective Behavior. Soc Probs. 1971; 18 298-306. doi:10.2307/799797. 


\section{Research and Best Practice}

Appendix 1. Questionnaire for experts

1 The CRC includes at art.24 the Right to Health as enjoyment of the highest attainable standard of health conducive to living a life in dignity, including associated rights related to economic and social determinants of health, involving access to health services, goods and facilities, encompassing fulfilment of all rights of provision, protection and participation. Very often there is discrepancy between principles and practices and this brings also to violations of the Right to Health.

If you agree with this affirmation could you indicate the main reasons why the principles are not put into action, with particular regard to the Children's Right to Health (please provide an example)?

2 In terms of efficacy of national policies addressed to children, which are in your opinion the critical aspects and the winning factors (please provide an example)?

3 Looking at the International level and in particular at the role of the UN Agencies and of the NGOs, where do you think reside the main difficulties and the winning factors to fill the gap between declaration and implementation of children's right to health (please provide an example)?

4 Looking at the role of health care systems, which are in your opinion the main obstacles to the application of a Child Right to Health based approach and in particular to the four Convention principles: Development and survival, Non-discrimination, Right to be Heard and Best interest of the child (please provide an example)? 